\title{
TESTING OF PROTOTYPE INTERFERENCE SCREW FOR ACL RECONSTRUCTION IN PORCINE FEMURS
}

\author{
József Gábor Kovács ${ }^{1}$, Péter Nagy ${ }^{1}$, Ákos Oroszlány ${ }^{1}$, Attila Pavlik ${ }^{2}$, Péter Hidas ${ }^{2}$ \\ ${ }^{1}$ Department of Polymer Engineering, Budapest University of Technology and Economics \\ ${ }^{2}$ Department of Sports Surgery, National Institute for Sports Medicine \\ kovacs@pt.bme.hu
}

\begin{abstract}
Multiple techniques for the reconstruction of anterior cruciate ligament (ACL) are available, most of which use implant made from metallic or bioabsorbable materials. Currently one of the most widely used fixation methods for anterior cruciate ligament reconstruction with bone tendonbone graft is the interference screw.

The aim of our work was to test custom design screw geometry, whether it is appropriate for ACL reconstruction. New screw was designed geometry for the work, so that screws with the same geometry could be produced for later work, from different materials. In this study injection molded biodegradable interference screws were tested on porcine femurs, with bone-patellar tendon-bone (BPTB) graft fixation. The average failure load and the stiffness $(772 \pm 225 \mathrm{~N}$ and $109 \pm 33.9 \mathrm{~N} / \mathrm{mm}$ respectively) of the fixation was higher than literature average, although within standard deviation. Test results showed that the designed screw geometry is adequate for BPTB graft fixation.
\end{abstract}

Keywords: anterior cruciate ligament, BPTB, interference screw

\section{Introduction}

Anterior cruciate ligament (ACL) reconstruction is one of the most common knee surgery since the ACL is torn most frequently in this joint. It causes in instability of the knee joint and requires surgical treatment in the active population. The success of ACL reconstruction is influenced by several factors. These include timing of the surgery, graft choice, tunnel placement, graft tensioning, graft fixation methods, and the postoperative rehabilitation program ${ }^{1,2}$. One of the most important factors is the security of the graft fixation ${ }^{3,4,5}$, especially in the early postoperative period, because the advantages of early motion during an accelerated rehabilitation have been shown in different studies. Although it was also shown that during active full extension of the knee, the resultant forces produced in the graft can attain $200 \mathrm{~N}^{6,7}$, most researchers calculated with a maximum of $500 \mathrm{~N}$ daily load, and $450 \mathrm{~N}$ in an intensive rehabilitation program ${ }^{6,8}$.

In the past two decades many different fixation method were developed, such as metal and biodegradable interference screws, post fixations by screws, staples, buttons, sutures and others $9,10,11,12,13$, and several new fixation methods are under development ${ }^{14,15,16,17}$. Most of these techniques use implants from metallic or absorbable materials ${ }^{18,19}$, which are later surgically removed or are absorbed by the body. Exception is the press-fit fixation, during which the BPTB graft is impacted into the bone without the help of foreign bodies ${ }^{20,21,22}$. These methods for ACL reconstruction must ensure the ultimate tensile strength and stiffness that allows the application of the current accelerated rehabilitation protocols $7,23,24$. 
Nowadays, the interference screw fixation is one the most popular method in ACL reconstruction, and there are several biomechanical studies proving its efficiency and good mechanical properties $25,26,27,28,29,30,31$.

During interference screw fixation of the BPTB (bone-patellar tendon-bone) graft there is an interlock between the screw threads and the bone (the bone block attached to the graft and the bone of the tunnel). This is due to the triangular cross sectional dimensions of the screw thread in the direction parallel with the screw axis. When loaded under tension a large shearing force is therefore required to break either the bone that engages with the thread, or the thread of the interference screw and cause pull-out. Since the cancellous bone is weaker most times than the metallic or bioabsorbable screw, it is the bone that will brake.

Fixation strength is mainly affected by the interlocking area of the screw, bone block and bone. The interlocking area is affected by the gap size, bone block cross-sectional shape, screw dimensions, etc. (Figure 1). Since both metallic and biomaterial used in orthopedic implants are stronger than cancellous bone the pull-out strength for identically shaped screws inserted with the same anatomical attributes (gap size, bone block cross-sectional shape, screw dimensions), should be similar ${ }^{32}$. The majority of original and review works show that bioabsorbable and metallic screws have similar failure loads $33,34,35$. Only a smaller number of works indicate that one screw is better than the other. In work reporting about comparative tests, most times only screw diameter and maybe length match between the two screws, thread depths and profile, head size, tine differ ${ }^{32,33}$

The aim of our work was to produce a biodegradable interference screw with adequate screw geometry for ACL reconstruction with BPTB graft. Further research will include change of screw material and screw geometry (tine, thread depth, tapering length etc.)

\section{Materials and methods}

14 fresh porcine knees were used, from animals between $1-1.5$ years and $100-130 \mathrm{~kg}$. The harvesting of the distal femurs, patellae and the patellar tendons and the measurements took place within 24 hours after death. The specimens were kept in plastic bags to prevent
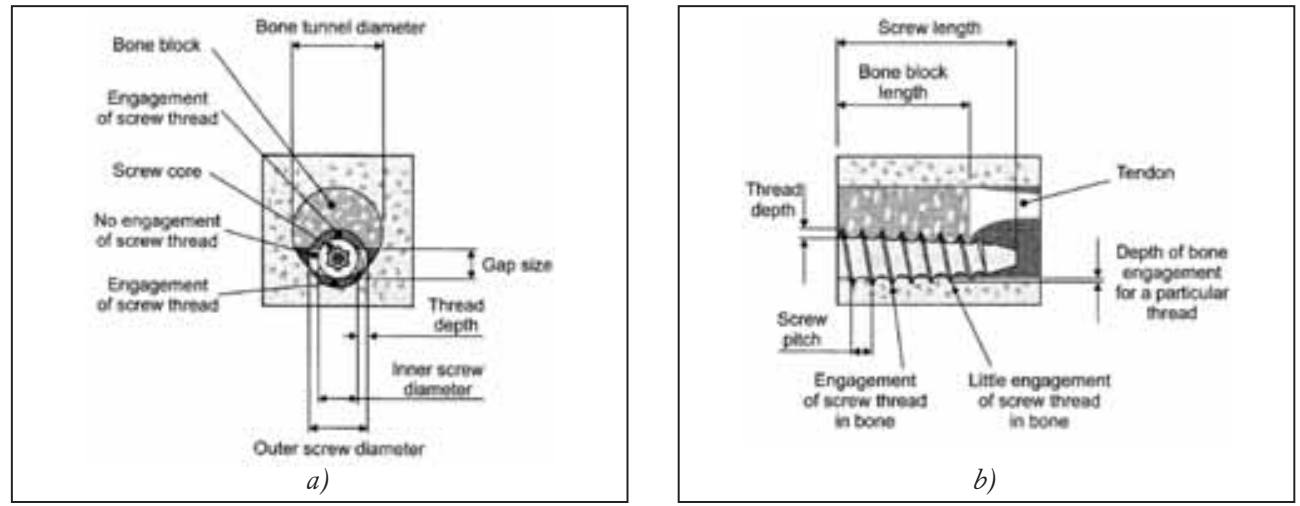

Figure 1. Characteristics of the interference screw when used to fix a bone block of the BPTB graft to the tunnel wall ${ }^{32}$

(a) End view (b) Side sectional view through bone tunnel and block 
dehydration, and the prepared specimens were tested right after preparation.

The specimens were prepared by removing all the soft tissue from the distal femur. The femoral tunnel was placed at the previous attachment of the anterior cruciate ligament. The cortex was removed at that site with a conventional drill, exposing the cancellous bone. The femoral tunnel was created with a conventional $10 \mathrm{~mm}$ drill. $8 \mathrm{~mm}$ wide central patellar bone-tendon-bone graft was harvested from the patellar tendon. The patellar end of the bone-tendon-bone graft was placed into the femoral socket with the tendon positioned posteriorly. The patellar semicircular bone plug measured $8 \mathrm{~mm}$ in diameter and $25 \mathrm{~mm}$ in length. The tibial end bone-tendon-bone graft was used for securing the graft in the testing machine.

The screws were injection moulded into a rapid prototyped mould from non medical grade PLA (NatureWoks 3051D) on an Arburg ALLROUNDER 320C injection molding machine. Medical grade materials was not necessary for the tests, as one of the main objective of this study was to test whether screw geometry and manufacturing technology are adequate for further research. Effect of screw geometry and manufacturing technology will be discussed in a later paper.

Screw design was determined after consulting with practitioner surgeons, performing ACL reconstruction ${ }^{36}$. The length of tapering of the screw end was chosen to be $1 / 3$ of the total screw length. The screw is fully cannulated, the screwdriver socket is hexagonal, and $17 \mathrm{~mm}$ deep. The pitch of the screw thread was cho$\operatorname{sen} 7^{\circ}$. The respective dimensions of the interference screw are illustrated in (Figure 2).

A computer-controlled testing device (Zwick Z020) was used for the pull-out tests. A spe-

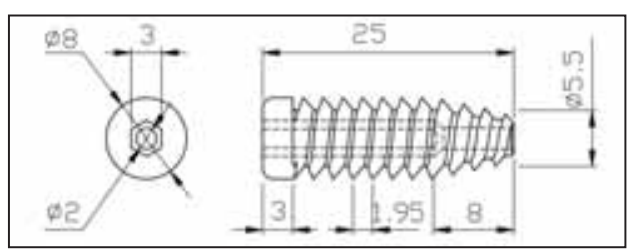

Figure 2. Main dimensions of the interference screws in $\mathrm{mm}$

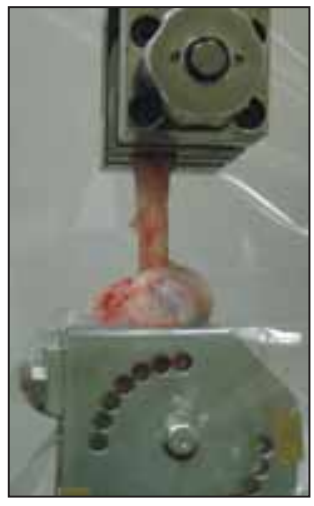

a)

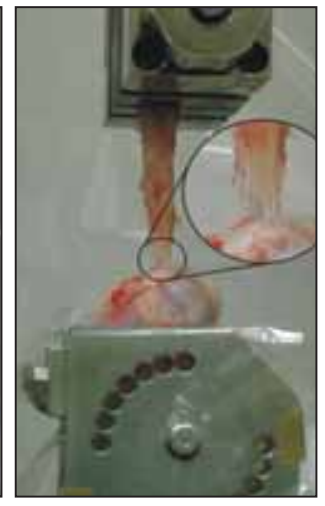

b)
Figure 3. Specimen preparation in Zwick testing machine (a) after pretension (b) during failure

cially designed holder was fixed on the base of the testing machine, and the crosswise (medial to lateral) drilled femur was joined to it with a metallic bolt. The tibial bone end of the BPTB graft was secured to the crosshead of the testing device (Figure 3). A pretension of $10 \mathrm{~N}$ was applied to the bone-patellar tendon complex and tensile-strength test was performed with a constant $200 \mathrm{~mm} / \mathrm{min}$ speed along the longitudinal axis of the tendinous part of the graft. Testing speed was chosen according to previous researches in this field at our department ${ }^{20}$.

The measured data were recorded on load-displacement diagrams of the testing device (Figure 4). Failure mode was also recorded even it was pull-out from the tunnel, intra substance ligament rupture or femoral bone breakage. Stiffness was calculated as the slope of the 


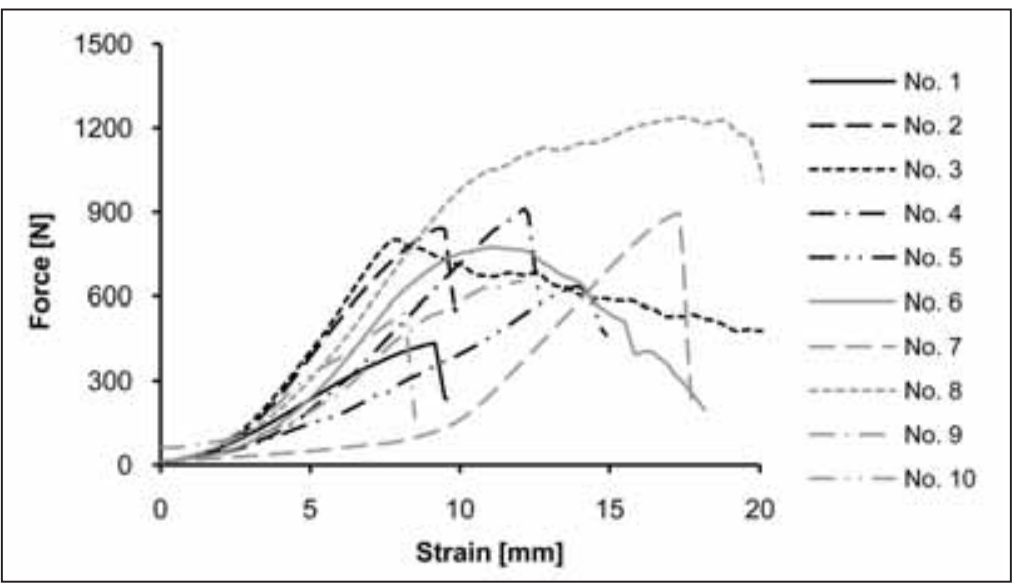

Figure 4. Force vs. displacement graphs of the valid tests

most linear part of the force-versus-displacement graph. Measured ultimate tensile strength and stiffness were compared to literature data.

\section{Results}

The results obtained from the pull-out test are summarized in Table 1. The mean failure load and stiffness was $772 \pm 225 \mathrm{~N}, 109 \pm 33.9 \mathrm{~N} / \mathrm{mm}$ respectively. Four types of failure modes were recorded. In four cases the pull-out force was smaller than $100 \mathrm{~N}$, these measurements were

\begin{tabular}{|c|c|c|c|}
\hline No. & $\begin{array}{c}\mathbf{F}_{\max } \\
{[\mathbf{N}]}\end{array}$ & $\begin{array}{l}\text { Stiffness } \\
{[\mathrm{N} / \mathrm{mm}]}\end{array}$ & Failure mode \\
\hline No. 1 & 435 & 63.5 & Tendon broke at bone plug \\
\hline No. 2 & 841 & 138.5 & Tendon broke \\
\hline No. 3 & 801 & 146.0 & Tendon broke \\
\hline No. 4 & 911 & 111.5 & Graft pull out \\
\hline No. 5 & 633 & 55.7 & Tendon broke \\
\hline No. 6 & 773 & 133.5 & Graft pull out \\
\hline No. 7 & 895 & 115.3 & Graft pull out \\
\hline No. 8 & 1237 & 147.5 & Tendon broke \\
\hline No. 9 & 654 & 104.2 & Tendon broke at bone plug \\
\hline No. 10 & 543 & 77.6 & Tendon broke at bone plug \\
\hline Mean & 772 & 109 & \\
\hline S.D. & 225 & 33.9 & \\
\hline
\end{tabular}

Table 1. Results obtained from pull-out tests not evaluated as the specimen inspection indicated a damaged tendon. In three cases the tendon tearing occurred after the stretching at the bone plug, leaving the bone plug and the screw behind. In four cases the tendon tore away from the bone plug, and in three cases the graft with the bone plug attached pulled out.

\section{Discussion}

The fundamental purpose of this work was to test a custom designed interference screw for ACL reconstruction with BPTB graft. Custom design was necessary since further goal was to compare effect of material, screw geometry etc. Such work can not be done with commercially available screws, since these differ in size, thread type, tine etc. ${ }^{12,37,38}$. In comparative works the bioabsorbable and the metallic screw sometimes come from different manufacturer, thus ensuring different geometry ${ }^{32,33,34,35}$. Most times only screw diameter and maybe the length match between the two screws, thread depths and profile, head size, tine differ ${ }^{32,33}$. Currently there are only standards for metallic bone screw threads for medical application (Figure 5) ${ }^{37,39}$. Most manufacturers use these thread for both their metallic and bioabsorbable screws ${ }^{37,38}$. Our novel screw design resembles 


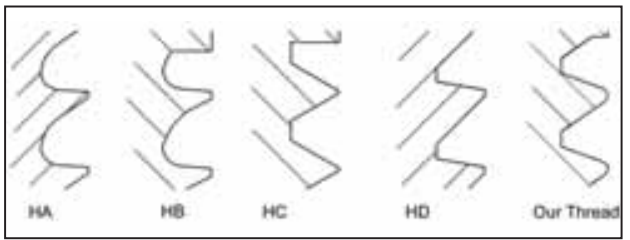

Figure 5. Standard metal bone screw threads for medical application compared to our own design ${ }^{37,39}$

mostly the HC and HD thread type. The steepness of both upper and lower side of the thread is in between of those from the standard thread types. This thread type was chosen considering the manufacturability with injection molding, and was finalized after consulting with practitioner surgeons ${ }^{40}$. The thread type used in this study can be seen on Figure 7 compared to standard medical treads.

One of the most important criteria for successful anterior cruciate ligament reconstruction is the primary stability of the graft $7,23,24$. As well as the strength of the graft material used for the replacement, the fixation is also of great concern with regard to the primary stability of the knee 27,30 . Several studies have found that during maximum tensile strength tests the failure occurs more often at the graft fixation site than within the ligamentous tissue itself $2,3,4,5$.

During our work four types of failure modes were recorded, one of which resulted in the exclusion of the specimens from being evaluated. In four cases the pull-out force was

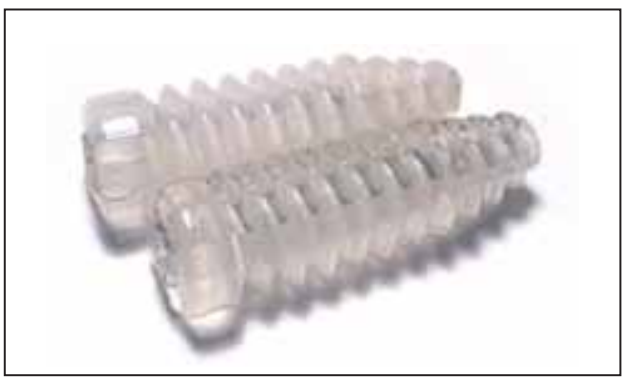

Figure 7. Samples of the interference screws used in this study

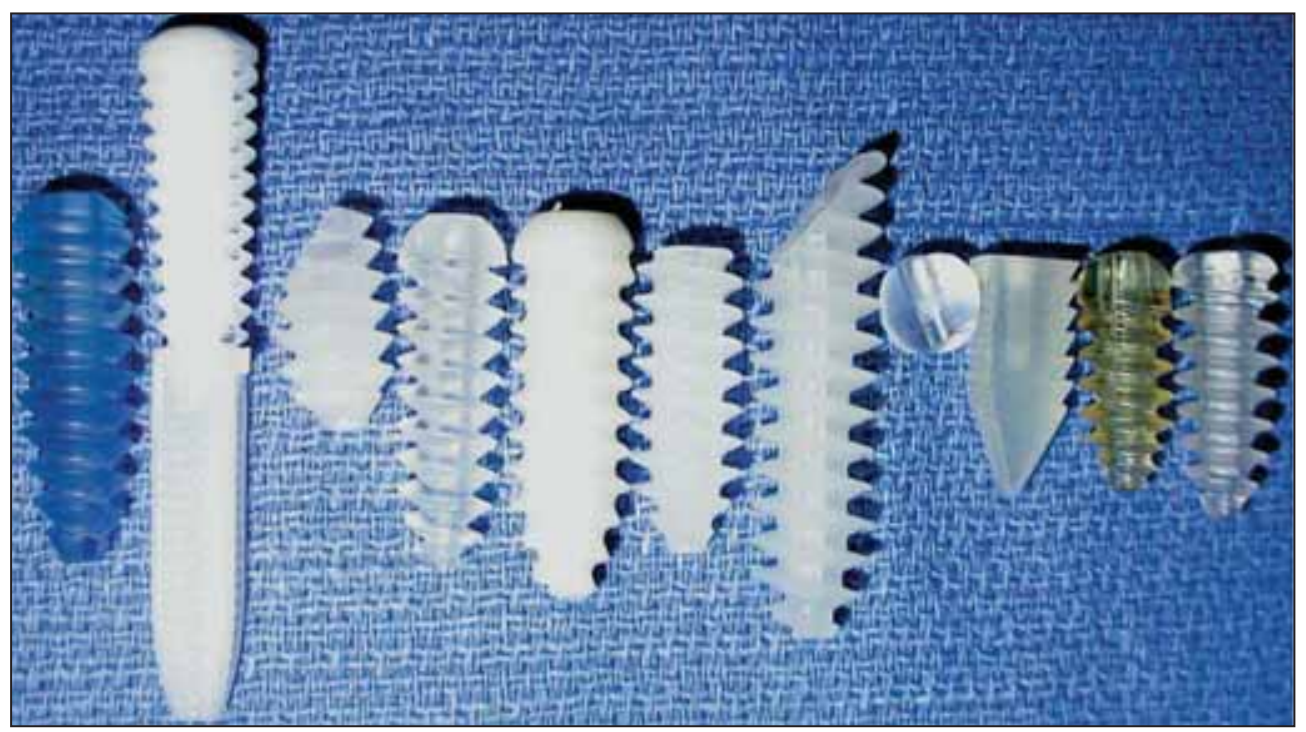

Figure 6. Sample of bioabsorbable interference fixation devices: Absolute (Mitek), Intrafix (Mitek), Bio-Cortical Distal (Arthrex), Sheathed Femoral (Arthrex), BioRCI HA (Smith \& Nephew), Bioscrew (Linvatec), Bioscrew Xtralock (Linvatec), EndoPearl (Linvatec), Wedge (Linvatec), Gentle Threads (Arthrotek), and Bioabsorbable Wedge (Stryker) (left to right) ${ }^{41}$ 


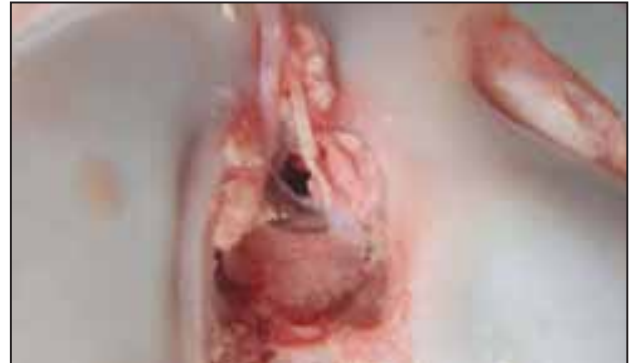

a)

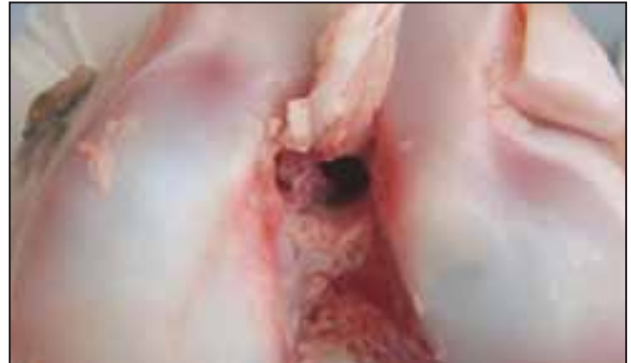

b)

Figure 8. Femur head after pull out tests (a) tendon separated from the bone, (b) tendon broke. In both cases the screw remained behind in the bone tunnel with cancellous bone from the graft

smaller than $100 \mathrm{~N}$. In these cases after closer inspection it was concluded that the tendon was damaged during fixation, which caused the premature failure of the graft. In three cases the tendon tearing occurred at the bone plug, after the stretching leaving the bone plug and the screw behind (Figure 8.a). In four cases the tendon tore further away from the bone plug, leaving the bone plug, the screw and a broken tendon behind (Figure 8.b). In three cases the graft with the bone plug attached pulled out of the bone tunnel. In all cases the screws were recovered from the femurs, after testing. No visible damage could be observed on the recovered screws.

According to Noyes ${ }^{42}$ the maximum failure strength of a human ACL was $1730 \mathrm{~N}$ with $182 \mathrm{~N} / \mathrm{mm}$ stiffness in young cadavers and $734 \mathrm{~N}$ with $129 \mathrm{~N} / \mathrm{mm}$ stiffness in old cadavers. Savio $\mathrm{Woo}^{43}$ measured similar strength and stiffness $(1503 \mathrm{~N}, 220 \mathrm{~N} / \mathrm{mm})$ on intact ACL in middle-aged specimens at 30 degrees of knee flexion and applied $200 \mathrm{~mm} / \mathrm{min}$ strain rate. Newer studies indicate the ultimate load of an ACL of a young adult can reach up to $2500 \mathrm{~N}^{44,45}$, and can have a stiffness of $306 \mathrm{~N} / \mathrm{mm}^{46}$.

The results of this study show, that the custom designed interference screw achieved a mean maximum load of $770 \mathrm{~N}$, which is slightly

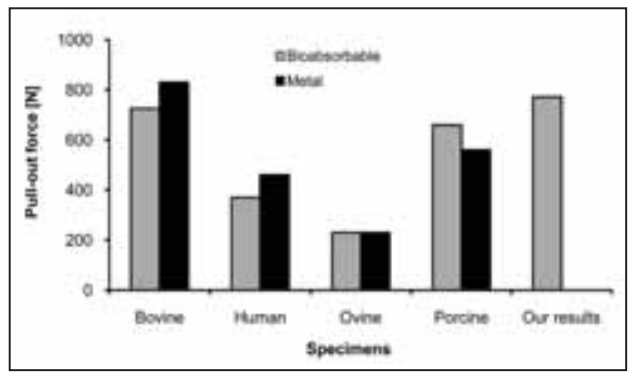

Figure 9. Average pull-out force results compared to literature data ${ }^{32}$

higher than literature average (Figure 9). Average stiffness was also well above reference data with $109 \mathrm{~N} / \mathrm{mm}$, but this is still far from the stiffness of a knee with an intact ACL.

Since data published in the literature consider ACL reconstruction fixation with maximum load above $450-500 \mathrm{~N}$ as adequate ${ }^{6,7,8}$, it was concluded that our custom designed interference screw is appropriate for further researches. These will include different screw materials, and changes in screw geometry.

\section{Conclusions}

The manufacturing technology used for the production of the screws is suitable for the production of small series of medical implants that can be used for biomedical tests in cadav- 
ers. The above average pull-out force does not indicate that the examined screw geometry is better than those available on the market, but does show that the custom designed interference screw used in our work is adequate for ACL reconstruction with BPTB grafts. This means that this screw geometry is a good base for further research, concerning screw material or geometry (tine, thread depth, tapering length etc). The higher average pull-out force could have been caused by several factors, such as animal type, bone tunnel diameter, bone plug size, gap size etc.

\section{REFERENCES}

1. Brown CH, Jr., Carson EW. Revision anterior cruciate ligament surgery. Clin Sports Med 1999 Jan;18(1):109-71.

\section{Honl M, Carrero V, Hille E, Schneider E, Morlock} $M M$. Bone-patellar tendon-bone grafts for anterior cruciate ligament reconstruction: an in vitro comparison of mechanical behavior under failure tensile loading and cyclic submaximal tensile loading. Am J Sports Med 2002 Jul-Aug;30(4):549-57.

3. Brand J, Jr., Weiler A, Caborn DN, Brown CH, Jr., Johnson DL. Graft fixation in cruciate ligament reconstruction. Am J Sports Med 2000 SepOct;28(5):761-74.

\section{Brown GA, Pena F, Grontvedt T, Labadie D,} Engebretsen $L$. Fixation strength of interference screw fixation in bovine, young human, and elderly human cadaver knees: influence of insertion torque, tunnel-bone block gap, and interference. Knee Surg Sports Traumatol Arthrosc 1996;3(4):238-44.

5. Kurosaka M, Yoshiya S, Andrish JT. A biomechanical comparison of different surgical techniques of graft fixation in anterior cruciate ligament reconstruction. Am J Sports Med 1987 May-Jun; 15(3):225-9.

6. Markolf KL, Gorek JF, Kabo JM, Shapiro MS. Direct measurement of resultant forces in the anterior cruciate ligament. An in vitro study performed with a new experimental technique. J Bone Joint Surg Am 1990 Apr;72(4):557-67.

7. Shelbourne KD, Nitz P. Accelerated rehabilitation after anterior cruciate ligament reconstruction. Am J Sports Med 1990 May-Jun; 18(3): 292-9.
8. Noyes FR, Butler DL, Grood ES, Zernicke RF, Hefzy MS. Biomechanical analysis of human ligament grafts used in knee-ligament repairs and reconstructions. J Bone Joint Surg Am 1984 Mar;66(3):344-52.

9. Pavlik A, Hidas P, Tállay A, Berkes I. Fixation methods following ACL reconstruction. I. The ideal graft fixation. Hun J of Trauma, Ortho, Hand Surg, Plastic Surg 2005;48(2):101-10.

10. Shelbourne KD, Urch SE. Treatment Approach to Anterior Cruciate Ligament Injuries. Oper Techn Sport Med 2009 Jan;17(1):24-31.

11. Wu JL, Yeh TT, Shen HC, Cheng CK, Lee CH. Mechanical comparison of biodegradable femoral fixation devices for hamstring tendon graft A biomechanical study in a porcine model. Clin Biomech 2009 Jun;24(5):435-40.

12. Fabbriciani C, Mulas PD, Ziranu F, Deriu L, Zarelli $D$, Milano $G$. Mechanical analysis of fixation methods for anterior cruciate ligament reconstruction with hamstring tendon graft. An experimental study in sheep knees. Knee 2005 Apr;12(2):135-8.

13. Henshaw DR, Rodeo $S A$. Noninterference screw bone block fixation devices. Oper Techn Sport Med 2004 Jul;12(3):195-9.

14. Bodo L, Hangody L, Borsitzky B, Beres G, Arato G, Nagy $P$, et al. Development of a tension-adjustable implant for anterior cruciate ligament reconstruction. Eklem Hast Cerrahisi 2008;19(1): $27-32$. 
15. Martel O, Carta JA, Garces G. A new device for the fixation of anterior cruciate ligament tendon grafts. Design and experimental study. Med Eng Phys 2007 Jan;29(1):163-8.

16. Black KP, Saunders MM. Expansion anchors for use in anterior cruciate ligament (ACL) reconstruction: Establishing proof of concept in a benchtop analysis. Medical Engineering \& Physics 2005 Jun;27(5):425-34.

17. Füles P, Goddard R, Madhav R, Yiannakopoulos $C$, Mowbray M. Anterior cruciate ligament replacement technique using four-strand semitendinosus-gracialis tendon autograft. Short term follow up results. Hun J of Trauma, Ortho, Hand Surg, Plastic Surg 2004;47(1):25-33.

\section{Lipik VT, Widjaja LK, Liow SS, Venkatraman} SS, Abadie MJM. Synthesis of biodegradable thermoplastic elastomers (BTPE) based on epsilon-caprolactone. Express Polym Lett 2010 Jan;4(1):32-8.

19. Tabi T, Sajo IE, Szabo F, Luyt AS, Kovacs JG. Crystalline structure of annealed polylactic acid and its relation to processing. Express Polym Lett 2010 Oct;4(10):659-68.

20. Pavlik A, Hidas P, Czigany T, Berkes I. Biomechanical evaluation of press-fit femoral fixation technique in ACL reconstruction. Knee Surg Sport Tr A 2004 Nov;12(6):528-33.

21. Pavlik A, Hidas P, Tallay A, Toman J, Berkes I. Femoral press-fit fixation technique in anterior cruciate ligament reconstruction using bonepatellar tendon-bone graft - A prospective clinical evaluation of 285 patients. Am J Sport Med 2006 Feb;34(2):220-5.

\section{Hertel P, Behrend H, Cierpinski T, Musahl V,} Widjaja $G$. ACL reconstruction using bonepatellar tendon-bone press-fit fixation: 10-year clinical results. Knee Surg Sport Tr A 2005 May; 13(4):248-55.

23. Amis $A A$. The strength of artificial ligament anchorages. A comparative experimental study. J Bone Joint Surg Br 1988 May;70(3):397-403.
24. Kühne J, Fottner M, Plitz W. Primärstabilität einer implantatfreien Verankerung des Lig.patellae-Transplantats beim vorderen Kreuzbandersatz. Unfallchirurg 1999;102(10):791-6.

25. Bryan JM, Bach BR, Jr., Bush-Joseph CA, Fisher $I M, H s u$ KY. Comparison of "inside-out" and "outside-in" interference screw fixation for anterior cruciate ligament surgery in a bovine knee. Arthroscopy 1996 Feb;12(1):76-81.

26. Hulstyn M, Fadale PD, Abate J, Walsh WR. Biomechanical evaluation of interference screw fixation in a bovine patellar bone-tendon-bone autograft complex for anterior cruciate ligament reconstruction. Arthroscopy 1993;9(4):417-24.

27. Kohn D, Rose C. Primary stability of interference screw fixation. Influence of screw diameter and insertion torque. Am J Sports Med 1994 MayJun;22(3):334-8.

28. Lemos MJ, Albert J, Simon T, Jackson DW. Radiographic analysis of femoral interference screw placement during ACL reconstruction: endoscopic versus open technique. Arthroscopy 1993; 9(2):154-8.

29. Lemos MJ, Jackson DW, Lee TQ, Simon TM. Assessment of initial fixation of endoscopic interference femoral screws with divergent and parallel placement. Arthroscopy 1995 Feb;11(1): 37-41.

30. Matthews LS, Lawrence SJ, Yahiro MA, Sinclair $M R$. Fixation strengths of patellar tendon-bone grafts. Arthroscopy 1993;9(1):76-81.

31. Rupp S, Krauss $P W$, Fritsch $E W$. Fixation strength of a biodegradable interference screw and a press-fit technique in anterior cruciate ligament reconstruction with a BPTB graft. Arthroscopy $1997 \mathrm{Feb} ; 13(1): 61-5$.

32. Beever D. Metal vs. Bioabsorbable interference screws: initial fixation. J Engineering in Medicine 2002;217(1):59-75.

33. Johnson $L L$, vanDyk GE. Metal and biodegradable interference screws: Comparison of failure strength. Arthroscopy 1996 Aug;12(4):452-6. 
34. Seil R, Rupp S, Krauss PW, Benz A, Kohn DM. Comparison of initial fixation strength between biodegradable and metallic interference screws and a press-fit fixation technique in a porcine model. Am J Sports Med 1998 Nov-Dec;26(6): $815-9$.

35. Hoffmann RF, Peine R, Bail HJ, Sudkamp NP, Weiler A. Initial fixation strength of modified patellar tendon grafts for anatomic fixation in anterior cruciate ligament reconstruction. Arthroscopy 1999 May;15(4):392-9.

36. Oroszlany Á. Development of special screws for medical application. GÉP 2010;61 (9-10):67-70.

37. Implants for surgery - Metal bone screws with hexagonal drive connection, spherical undersurface of head, asymmetrical thread - Dimensions; ISO 5836:1991.

38. Lu AP, McAllister DR. Metal interference screws. Oper Techn Sport Med 2004 Jul;12(3):176-9.

39. Implants for surgery - Metal bone screws with conical under-surface of head - Dimensions; ISO 9268:1988.

40. Oroszlany A, Kovacs JG. Gate type influence on thermal characteristics of injection molded biodegradable interference screws for ACL reconstruction. Int Commun Heat Mass 2010 Aug; 37(7):766-9.
41. Purcell DB, Rudzki JR, Wright RW. Bioabsorbable interference screws in ACL reconstruction. Oper Techn Sport Med 2004 Jul;12(3): 180-7.

42. Noyes FR, Grood ES. Strength of Anterior Cruciate Ligament in Humans and Rhesus-Monkeys. Journal of Bone and Joint Surgery-American Volume 1976;58(8):1074-82.

43. Woo SL, Hollis JM, Adams DJ, Lyon RM, Takai S. Tensile properties of the human femur-anterior cruciate ligament-tibia complex. The effects of specimen age and orientation. Am J Sports Med 1991 May-Jun;19(3):217-25.

44. Beynnon BD, Fleming BC, Johnson RJ, Nichols $C E$, Renstrom PA, Pope $M H$. Anterior cruciate ligament strain behavior during rehabilitation exercises in vivo. Am J Sports Med 1995 JanFeb;23(1):24-34.

45. Frank $C B$, Jackson DW. The science of reconstruction of the anterior cruciate ligament. J Bone Joint Surg Am 1997 Oct;79(10):1556-76.

46. Rowden NJ, Sher D, Rogers GJ, Schindhelm K. Anterior cruciate ligament graft fixation. Initial comparison of patellar tendon and semitendinosus autografts in young fresh cadavers. Am J Sports Med 1997 Jul-Aug;25(4):472-8.

This paper was supported by the János Bolyai Research Scholarship of the Hungarian Academy of Sciences. This work is connected to the scientific program of the "Development of quality-oriented and harmonized $R+D+I$ strategy and functional model at BME" project. This project is supported by the New Hungary Development Plan (Project ID: TÁMOP-4.2.1/B-09/1/KMR-2010-0002)

\section{Dr. Kovács József Gábor}

Department of Polymer Engineering, Budapest University of Technology and Economics H-1111 Budapest, Múegyetem rkp. 3.

Tel.: (+36) 1 463-1440 